- Rape crisis centres. These are located in many city centres and also offer counselling services. The umbrella organisation, the Rape Crisis Federation (RCF), acts as a referral service to individual women who are seeking advice and/or support around the issues of rape or sexual assault. For further information see the editorial on pages 120-122.

- Victim Support. This is a national charity that helps people cope with crime. For further information see the editorial on pages $122-123$.

Statements on funding and competing interests

Funding. None declared.

Competing interests. None declared.
Further reading

Ledray LE. Recovering from rape. New York, NY: Henry Holt and Company, 1994. Matsakis A. I can't get over it - a handbook for trauma survivors. Oakland, CA: New Harbinger Publications, 1996.

Author's Note. Throughout this article, because women are the primary victims of rape, the victim is referred to as she. This is not intended to exclude or discount men who have been the victims of such assaults.

Editor's Note. This editorial has been written from the perspective of a victim living in England or Wales. The legal experience may differ slightly in Scotland due to differences in Scots law. For further information see the editorial on pages $115-117$.

\title{
The problem of rape and supporting victims
}

Currently, the crimes of rape and sexual assault and the extent of their impact on victims appear to be the least understood by professionals and policymakers in comparison to other crimes. This is in contrast to policy on domestic violence, where there has been considerable change over the last 25 years in both institutional attitudes towards its 'relative acceptability', and in developing social policies and practices to support victims and deal with perpetrators. Whilst there are the beginnings of a sea change in relation to rape and criminal justice policy, 1,2 the idea of rape as a widespread social problem that inflicts considerable social harm still needs to be developed.

This lack of understanding about the problem of rape can be partially explained by the prevalence of myths and stereotypes, which Kelly ${ }^{3}$ defined as 'real' rape and 'real' victims of rape. Kelly suggests that there is a social 'template' of what constitutes 'real' rape. This involves rape by a stranger at night in a public place and the use of physical force or threats of physical force. Thus, the idea of 'real' rape contributes to negative institutional responses towards rape victims who do not fit this template but who, according to the research and victim surveys both in the UK and elsewhere, constitute the majority of rape victims. ${ }^{3,4}$ These studies indicate that stranger rape is less common than rape which is perpetrated by men who know their victims to a greater or less extent. Moreover, whilst there has been no UK study focusing on prevalence, a recent US prevalence study (cited in Kelly ${ }^{3}$ ) indicated that almost one in five women experienced rape or sexual assaults over a lifetime, 'a large proportion of victimisations occurred when the victim was aged under 18 years', and the majority of 'adult assaults (76\%) involved current or ex-partners or a date'.

\section{Forms of 'known' rape}

Forms of 'known' rape can range from women who meet the perpetrator through casual social contact (for example, in bars) and initial dates. This is officially known as acquaintance rape, although these forms are often all conflated and named in the press as 'date rapes'. 'Partner rape' is where the woman has an ongoing relationship with the perpetrator and this includes rape in marriage.

Younger women may be seen as particularly vulnerable to acquaintance rape, and may be specifically targeted by some perpetrators, ${ }^{5}$ whilst older women are most affected by partner rape. ${ }^{3,4}$ However, all these latter forms of rape attract greater social assumptions of victim blame and/or assumptions that victims are less affected by such experiences.

In relation to acquaintance rape there are examples of numerous common beliefs that are based on prevailing sexual double standards where women are seen to invite or deserve rape. ${ }^{5}$ Thus young women may be viewed as 'leading men on' and provoking men's 'uncontrollable' sexual impulses through their own social behaviour. They may also attract blame for consuming alcohol, which itself may be perceived as inviting rape, or by perpetrators as a means of facilitating rape. 'Drug-assisted' rape also falls into this category. Alternatively, such rapes can be trivialised by being viewed as miscommunication, rather than deliberate assaults, and can contribute to calls for treating such rapes as less serious in the criminal law. However, this is an approach that has been rejected by the Home Office in its recent review of the way the law regards sexual offences, ${ }^{1}$ where it states: 'It is harder to see how degrees of rape could be defined - when does a stranger become an acquaintance or a friend? The crime of rape is so serious that it needs to be considered in its totality rather than being constrained by any relationship between the parties ... there is neither justification nor robust grounds for grading rape into lesser or more serious offences.'

However, these kind of assumptions also contribute to some victims believing that their experiences are not 'real rape', and contribute to internalised self-blame. Partner and ex-partner rape may also be seen as not as serious as rape by a stranger, ${ }^{6}$ partly because once a woman has agreed to enter into a (long-term) relationship with a man it is assumed that she has consented to have sex with him on any occasion for all time. Research on partner rape shows it may often overlap with domestic violence and can be part of an 
overall pattern of long-term domination and control where women are viewed as sexual possessions who can be subjected to repeated sexual and violent assaults. In the case of ex-partners, rape may also be used as a means of inflicting humiliation and revenge on the woman for leaving the relationship. Data from the most recent national crime survey, ${ }^{7}$ which for the first time asked questions about rape, indicates that the majority of victims were raped by partners and ex-partners but less than one-third told anyone at the time of the rape. In these circumstances, Myhill and Allen (cited in Kelly ${ }^{3}$ ) state that women may fear they will not be believed by close family and friends, they may experience shame, and may also fear reprisals from the perpetrator's family or friends or from the perpetrator himself. ${ }^{3}$

\section{The experiences of victims who contact rape crisis centres}

Data from rape crisis centres can provide much needed further information on victims' experiences and the men who perpetrate rape. Due to previous lack of funding, the Rape Crisis Federation (Wales and England) (RCF) has only recently begun to collect more detailed data. The initial setting-up of systems to enable data collection is still in its very early stages, so the statistics available remain very general. For example, in the past year member groups of the RCF received over 80000 calls from victims/survivors or supporters seeking help for victims and tends to confirm other research that most knew their perpetrators. From unpublished data collected by the RCF, $56 \%$ of the calls were from adult survivors of rape or sexual assault in childhood, mainly undertaken by family members and relatives. This indicates that such assaults have profound long-term impacts. Moreover, those counselling adult survivors suggest that many women who make contact have previously tried to bury their experiences and were either disbelieved or felt unable to tell anyone about the assaults at the time because of fear of disbelief or threats from perpetrators.

The work of rape crisis groups in supporting women and girls who have been subjected to such sexual assaults suggest there is no single common reaction to such bodily and mental violation whatever the specific form of rape or assault. In line with the research on this issue, ${ }^{8-10}$ assumptions that rape by a friend, partner, ex-partner or family member are less traumatic than stranger rape are not borne out by women's experiences. Some victims can perceive the betrayal of trust as having more profound longterm impacts and can have extensive effects on their selfimage. Moreover, the crime of rape is unique in the particular health consequences it can have for victims, through sexually transmitted diseases, human immunodeficiency virus (HIV) and unwanted pregnancy.

Those counselling survivors also find that women use different 'coping' mechanisms to try and deal with the degradation, humiliation, fear and control that has been inflicted on them by perpetrators in forcing sex on them against their will. Whilst some are highly distressed, others may be far more controlled. Some may attempt to block out their experiences in the immediate or longer term, whilst others may go through what are often viewed as stages of trauma. They move from initial shock and numbing of feeling, to anger, recurring nightmares, ritualised behaviour, extreme fears, and internalised feelings of guilt, shame and self-blame because they feel they could have done something to avoid being raped. Longer-term impacts may involve self-harm, depression and suicidal attempts. Even where women gradually regain control over their daily lives, events, dates or situations may revive traumatic responses. Such experiences can also be exacerbated where women are repeatedly abused, as in partner rape, which can also often be accompanied by severe physical violence or psychological terrorisation. However, many women are also able with support from others to overcome its destructive impacts and may become activists against male sexual violence.

\section{The Rape Crisis Federation (RCF)}

The RCF, established in 1996, aims to co-ordinate services to victims and provide a national voice for local rape crisis groups, which offer support, information and (in some areas) counselling to women and girls who have experienced rape, assault, childhood sexual abuse and sexual harassment. Whilst recognising that a minority of boys and men also experience sexual assault, since most assaults are on women and girls, services are provided only for this group, and the former are referred on. The RCF acts as a central referral service for individuals seeking help, provides minimum standards for rape crisis groups, raises public awareness of the issues, and supports campaigns to end rape and gain justice for victims.

There are currently 48 rape crisis groups which are members of the RCF across England and Wales, some of which have had considerable experience in supporting survivors of sexual violence for over 20 years. The majority of these local groups, at a minimum, offer a free confidential telephone helpline service, where a woman or girl who has experienced rape, sexual assault, childhood sexual abuse or any form of sexual harassment can expect to be believed, and receive non-judgmental support and be given further information. Most rape victims face a general climate of disbelief and blame; either for the rape or the way they have dealt with the rape. The centres therefore offer non-directive support which focuses on the individual woman's own choices. Empowerment is important in restoring self-belief and the women gaining control over their own bodies. Women can also be supported if they wish to report the assault(s) to the police. Many groups also offer survivor groups where women can meet together and support each other.

Depending on the resources available to different centres, they may also be able to offer face-to-face counselling, and support for parents, partners and carers of survivors. Some groups may also undertake education and training in their local communities and be able to offer training to professional groups and education in schools, on the prevention of male sexual violence. The vast variation in the provision of service, however, relates to the fact that there is no statutory funding of specific support services for victims of sexual assaults, unlike in other countries such as Ireland, even though there is beginning to be some official recognition of 'the severity of the impact on victims' of this kind of crime. ${ }^{2}$ However, in a number of areas trained volunteers run services entirely or in the main. For example, in Wales there is only one paid worker, and this situation demonstrates how far there is to go in developing adequately funded services for rape victims.

The RCF website provides information for professionals aiming to find support and help for victims/survivors, and information about local helplines and counselling services. This site also provides further information on understanding victims'/survivors' experiences of rape and sexual assault in childhood, and ways of offering support and can be found at www.rapecrisis.co.uk 

the investigation and prosecution of cases involving

Kelly L. A research review on the reporting, investigation and prosecution of rape cases. London, Her Majesty's Crown Prosecution Service Inspectorate, 2002.

Temkin J. Reporting rape in London: a qualitative study. Howard J Crim Justice 1999; 38:

\section{One in four: Providing emotional support to female victims of domestic violence}

It is estimated that one woman in four suffers domestic violence at some time in her life and that domestic violence accounts for one-quarter of all violent crime. According to the 2001 British Crime Survey, there were 499000 cases of domestic violence in England and Wales. ${ }^{1}$ Two women are killed every week by an abusive partner. ${ }^{2}$

Domestic violence can include verbal abuse, restrictions on contact with family members or friends, threats, physical assaults, rape and, ultimately, murder. Increasingly, men who have suffered domestic violence are coming forward to report abuse at their hands of their partners, both male and female. It should be noted here that Victim Support fully recognises that domestic violence does not only impact on women, and that its services are available equally to male and female victims and those in same-sex relationships. It is generally recognised by professionals in the social care sector that domestic violence is rarely a one-off event and can become increasingly serious and more frequent over time.

Victim Support is the national charity that helps people cope with crime. The organisation's community-based local groups, the Witness Services (based in the criminal courts) and the Victim Supportline, all have regular contact with female victims of domestic violence. Trained staff and volunteers offer emotional support, practical help and information - on a free and confidential basis - to more than one million victims of crime (including victims of domestic violence) every year.

As well as providing services to victims and witnesses, the organisation campaigns regularly for the introduction of criminal justice and social policies that take into account the needs and interests of victims of crime and witnesses. In February 2002, Victim Support's major campaign, Criminal Neglect ${ }^{3}$ called for a collaborative response from agencies and organisations outside the criminal justice system to address victims' and witnesses' needs.

The Criminal Neglect report insists, and demonstrates, that many victims of crime are effectively re-victimised by insensitive and inappropriate treatment by agencies and organisations, including housing providers, insurance companies and health care professionals. For example, the campaign urged health care professionals, particularly in accident and emergency departments, to be more aware of the effects of crime on patients and to offer them information about other agencies. Victim Support is aware that many victims of domestic violence will not go to the police as their first port of call, and could subsequently be faced with a lack of information and understanding in hospitals when they present their injuries to staff.

Key to Victim Support's success in helping victims of domestic violence is the organisation's multi-agency approach. The charity's Code of Practice states that 'Victim Support has a role in developing effective service provision for victims of domestic violence, working in partnership with other local agencies, to ensure the best use of resources'. 4

The STAR Project (Survival Through Abusive Relationships) is an example of how Victim Support uses this approach to help address the needs of women who are affected by domestic violence. It was set up as a result of a partnership between the Women's Project (which carried out the research that identified the need for the project) and Victim Support Avonvale's North Somerset Schemes. NSDAF (North Somerset Domestic Abuse Forum), North Somerset District Police, the North Somerset Community Legal Services Partnership and the Soroptimists have all lent their support to the initiative. Victim Support Avonvale describes the aim of the STAR Project as 'providing positive advice as to a person's choices together with appropriate practical support'. 5 In 2000, the Project received 30 domestic violence referrals; in 2001, that number had risen sharply to 117 referrals. ${ }^{5}$

One of the Project's volunteers describes her 2 years' work as rewarding because, she says, it enables women to make decisions for themselves. 'They can plan in advance what they are going to do if they decide to leave, rather than suddenly find themselves in a situation of having to sort things out at a difficult and inconvenient time. Some women do not want to leave but by knowing the choices that are available to them, they are more able to live with the situation. 5

Listening to abused women is important work for staff and volunteers at the Victim Supportline. Currently, the Supportline receives around 1650 calls a month (G Gridley, personal communication) from victims of a wide variety of crimes, and for some people it is their first point of contact after a crime. Between 2000 and 2001, the Victim Supportline took 17922 calls, 1369 of which were from victims of domestic violence. ${ }^{6}$

It is clear that, soon after an incident, many people want to talk to somebody. They need to make sense of the crime and want to know why they have, apparently, been singled out. When the phone rings in the Supportline office, the crime could range from a mobile phone theft or a burglary, to an abusive relationship, a rape or the murder of a relative. 